\title{
A Study of Agricultural Zoning of Huang-Huai-Hai Plain Based on GIS*
}

\author{
Manping Hou ${ }^{1}$, Jinmin $\mathrm{Hao}^{2, * *}$, Ying $\mathrm{Shi}^{3}$, Jun Yang ${ }^{4}$, Qian Wen ${ }^{5}$, \\ Mingzhu $\mathrm{Cha}^{3}$, and Lingkun Xiong ${ }^{4}$ \\ ${ }^{1}$ China Institute of Defense Science and Technology, Beijing 101601, China \\ ${ }^{2}$ China Agricultural University, Beijing 100193, China \\ ${ }^{3}$ Tianjin Polytechnic University, Tianjin 300387, China \\ ${ }^{4}$ Hunan Agricultural University, Changsha 410128, China \\ ${ }^{5}$ Henan Agricultural University, Zhengzhou 450002, China \\ jmhao@cau.edu.cn
}

\begin{abstract}
Many scholars in China have done a lot of research on regionalization of agricultural resources in the Huang-Huai-Hai Plain, but there is no quantitative research on agriculture of the whole plain. By using qualitative and quantitative analysis based on the basic data collected over 300 counties in the Huang-Huai-Hai Plain, considering such indicators as the natural resources of the plains and the yields of major crops and agricultural GDP, this paper designed the agricultural zoning of the plains. The Plain was classified into high-yield areas and low-producing areas. High-yield areas were divided into advantageous regions of foodstuff, advantageous regions of cotton, advantageous regions of oil, advantageous regions of foodstuff and cotton, advantageous regions of foodstuff and oil, advantageous regions of cotton and oil, and advantageous regions of foodstuff, oil and cotton. And these areas have been divided specifically. The research is of referential values for agricultural development of the Huang-Huai-Hai Plain, both practically and theoretically.
\end{abstract}

Keywords: Agricultural zoning, Producing Region Distribution, Agricultural Pattern, Huang-Huai-Hai Plain.

\section{Introduction}

Huang-Huai-Hai Plain is the largest plain in China. Land area accounts for about 30\% of the plain area of the whole country and arable land accounts for 1/6. Its climate is advantageous for both the north and the south, and has great potential for agricultural development with higher level of modern agricultural technology. Agricultural zoning layout plays a decisive role in agricultural production in this region. Researchers abroad have done many studies in the regionalization of agricultural resources[1-7]. The author collected agricultural economic data of each county of the Plain, and used GIS

\footnotetext{
* Supported by National Scientific and Technological Project(2004BA508B01).

** Corresponding author.
}

D. Li and Y. Chen (Eds.): CCTA 2012, Part II, IFIP AICT 393, pp. 84-91, 2013.

(C) IFIP International Federation for Information Processing 2013 
platform for property analysis, and drew a more reliable quantitative foundation, and provided the basis for sustainable development of agriculture in the Plain.

\section{Data Sources and Research Methods}

\subsection{Data Sources}

The research data included more than 300 counties' crop yields and county agricultural economic data from 2000 to 2006, natural agricultural resources and distribution of property, administration zoning map in the Plain. The data comes mainly from the China Statistical Yearbook, the China Agricultural Statistical Yearbook and regional investigation team.

\subsection{Data Processing and Research Methods}

Soil properties, water conditions, and crop yields for cotton, foodstuff and oil and agricultural GDP are main indicators in this research. Firstly, oil distribution and its suitability, the status of water resources were analyzed, and similar property areas were classified in the same district. According to the level of natural resources, the Plain is divided into piedmont plains, Heilonggang region, Shandong west plains, Henan southeastern plain, Anhui northern plain. Secondly, using Mapgis, the author scanned related county's administrative zoning map, and digitized each county boundary, then synthesized polygons and checked the polygons and formed a complete polygon library. Data attributes that included county agricultural production and agricultural economic data were given to each polygon in the database. Considering the yield of foodstuff, oil and cotton from 2000 to 2006 in the whole country and this district, the production partition standard was determined as high yield: foodstuff yield $\geq 5250 \mathrm{~kg} \cdot \mathrm{hm}^{2}$, cotton yield $\geq 1275 \mathrm{~kg} \cdot \mathrm{hm}^{2}$, oil crops yield $\geq 3000 \mathrm{~kg} \cdot \mathrm{hm}^{2}$; middle and low yield: foodstuff yield $<5250 \mathrm{~kg} \cdot \mathrm{hm}^{2}$, cotton yield $<1275 \mathrm{~kg} \cdot \mathrm{hm}^{2}$, oil crops yield $<3000 \mathrm{~kg} \cdot \mathrm{hm}^{2}$. Based on this data, using Mapgis Spatial analysis function, production partition advantage figure was obtained. The advantageous figure included advantageous regions of cotton, advantageous regions of foodstuff, advantageous regions of oil, advantageous regions of foodstuff and oil, advantageous regions of cotton and oil, advantageous regions of foodstuff and cotton, advantageous regions of foodstuff, oil and cotton, middle and low yielding regions of foodstuff, oil and cotton (Figure 1).

In the end, considering the two processes, the area was designated as high-yielding area, low-producing areas. High yielding regions was subdivided into seven more favorable areas and those production areas are laid and planed.

\section{The Huang-Huai-Hai Plain Agricultural Zoning}

\subsection{High-Yield Region Agricultural Overall Zoning}

Mainly high-yielding area in the Plain related to the favorable conditions of water, soil, light, heat and other natural agricultural resources. High yielding regions were divided 
into seven advantageous regions: advantageous regions of foodstuff, advantageous regions of cotton, advantageous regions of oil, advantageous regions of foodstuff and cotton, advantageous regions of foodstuff and oil, advantageous regions of cotton and oil, advantageous regions of foodstuff, oil and cotton. In order to stabilize the total wheat production in the areas, the result indicated that the optimum method is to moderately reduce wheat acreage of the severe water shortage areas, and vigorously develop high-quality wheat, and expand the area of high-protein, high-fat, high starch content of corn, and accelerate the development of feed industry, brewing industry, and promote the conversion of corn processing, and actively develop high-protein soybean and other oilseeds, and form a stable cotton focus area[6]. Under the premise of ensuring food security, the overall layout is that the plain should focus on diverse production and operation where agricultural products (especially special agricultural products) plays a dominant role, and that the plain can achieve a large-scale production and industrial management, by scale land management and using modern technology and the developing socio-economic conditions.

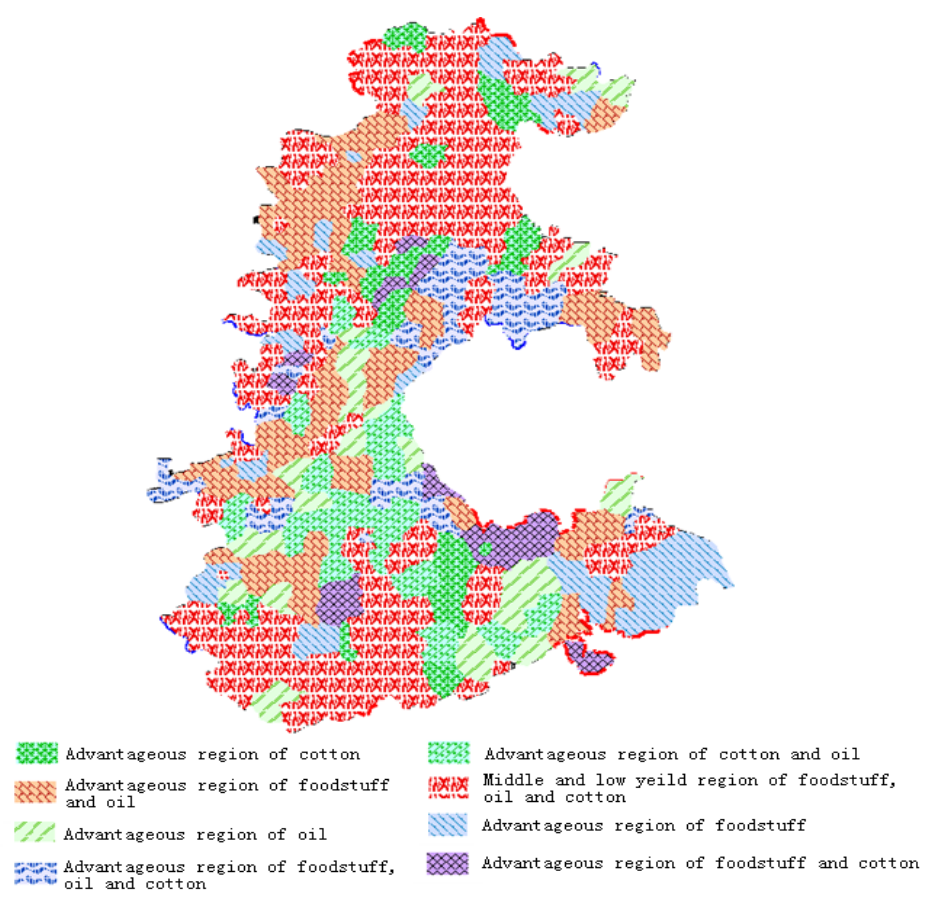

Fig. 1. Distribution Map of Foodstuff, Oil and Cotton Producing Region in Huang-Huai-Hai Plain

\subsubsection{High-Yield Area Zoning}

Advantageous regions of foodstuff, oil and cotton mainly include 14 counties in northern of Shandong west plains, 6 counties in Henan southeast plains, 4 counties in 
piedmont and the Anhui north plains. Advantageous regions of foodstuff and oil mainly include 25 counties in piedmont, 16 counties in Henan southeast plains, 10 counties in Shandong west plains, 6 counties in Anhui north plains. Advantageous regions of foodstuff and cotton were smaller in numbers, mainly including 5 counties in heilonggang region, 2 counties in Anhui plain, 2 counties in Henan southeast plains and 2 counties in Shandong west plains. Advantageous regions of cotton and oil mainly include 8 counties in Henan east plains, 7 counties in southern of Shandong west plains, 3 counties in Anhui north plains and 1 county in the southern of piedmont. Advantageous regions of foodstuff mainly include 11 counties in piedmont plains, 6 counties of Henan southeast plains, 9 counties in Anhui north plains and 1 county in Western Henan. Advantageous regions of cotton mainly include 8 countries in heilonggang region, 6 countries in Anhui north plains and 4 countries in Shandong west plains. Advantageous regions of oil mainly include 4 counties in the piedmont, 9 counties of Henan southeast plains, 5 counties in west Shandong plain and 5 counties in Anhui north plains. In addition, from the analysis of wheat, corn favoring areas distribution, wheat favoring areas are mainly in the piedmont plains, corn favoring areas are mainly in Shandong west plains. Wheat and corn favoring areas are mainly in the central region of the piedmont.

\subsubsection{Agricultural Pattern of the High Yield Region}

Based on water-saving cultivation, high-yielding zones had food production advantages, and optimized food variety and quality of structure and established top quality and high yield and efficient bulk agricultural commodity base of animal husbandry products. Advantageous regions of foodstuff and oil crops mainly produce special wheat, corn, oil and other pollution-free agricultural products. Advantageous regions of cotton produce high quality cotton in the main stream. Meanwhile, high-yielding zones moderately develop aquaculture industry to ensure food security objectives and quality efficiency objectives of the plains and the country are reached. In high-yielding areas of favorable conditions, production of mechanization, information technology and standardization was firstly implemented and then a model for the mechanization and modernization of agriculture was set in the country. High-yielding zones should develop processing industries to increase agricultural production and famers' income, and realize sustainable development of agriculture, the rural economy and ecological environment ultimately.

(1) Advantageous region of foodstuff, oil and cotton: soil and water resources in here is very advantageous. It is suitable for planting wheat, corn, cotton, oil etc. The area should be featured with a variety of crops of high quality varieties of foodstuff, oil and cotton in the future. Taking advantage of high yield of wheat and rich soil and water resources, the region should develop both summer and autumn planting, but can't expand the total acreage of wheat. In order to improve resource utilization, the region should be developed mainly in autumn. This region should form a scale and specialized cultivation of wheat, corn, cotton and oil quality product, also take advantage of companies (enterprises) with farmers and other forms, and form large-scale product processing bases, and moderately develop fodder cultivation, forest products and 
aquatic products, and form small-scale animal husbandry. In addition, it should increase planting of other crops with a dominant market position, and develop export-oriented agriculture. This area will become the first agricultural product advantageous district in the Plain.

From 2000 to 2006 in this area, average proportion of the acreage of foodstuff, cotton, oil was $12.50: 2.45: 1$, and wheat and corn is $1.48: 1$; Average ratio of total output value of agriculture, forestry, animal husbandry, fisheries was 28.50:1:12:2.1. As for improving foodstuff, cotton and oil cultivation structure, addition of feed grown, improvement of water-saving efficiency, ratio of foodstuff, cotton, oil, and feed may reach 8:3:1.5:1. Average ratio of total output value of agriculture, forestry, animal husbandry, and fisheries may reach $25: 1: 11: 2.5$ recently. And structure of wheat and corn is basically unchanged.

(2) Advantageous regions of foodstuff and oil: the zones are mainly located in the piedmont, the southeast Henan plains, Shandong west plains and Anhui north plains. The area of its water resources are relatively abundant ${ }^{[7]}$. Its soil is mainly cinnamon soil, and then moisture soil. Piedmont does not only have the most advantageous soil and water conditions, but also is good farmland construction areas. It has a high degree of land use. Its arable land reserve resource is rare, and is the more favorable areas of wheat. Northern piedmont is the common advantageous areas of wheat, corn-producing. Henan southeast plains areas are the more favorable areas of the wheat, the Shandong west plains area and Anhui north plains are the more favorable areas of the corn. Piedmont in northern areas should be based on the development of wheat, corn, oil and should make a modest reduction in cotton. Southern piedmont areas and Henan southeast plain areas should be based on the development of wheat, oil and should make a modest reduction in corn and cotton. Shandong west plains and Anhui north plains should be based on the development of corn and oil crops and should make a modest reduction in wheat and cotton. At the same time, the region should intensify production in the drought and saving water special crops, and implement large-scale cultivation, and develop intercropping systems and increase the proportion of summer crops, the acreage of forage crops and other economic crops. Forest in piedmont and southeast Henan plains areas is appropriate to increase the acreage of fruit trees. The region should achieve the integrated development of food, cash crops (except cotton) and fodder crops, and use industrial production and grain and oil processing industry to promote agricultural production. Henan southeast plains, Shandong west plains, Anhui north plains should be increased mechanization acreage.

From 2000 to 2006, average proportion of the acreage of foodstuff, cotton, oil, fruit in this area is $28.2: 1: 6.5: 3.70$, and wheat and corn is 1.2:1; Average ratio of total output value of agriculture, forestry, animal husbandry, fisheries is 150:1:98:8. As for improvement of foodstuff, cotton and oil cultivation structure, addition of feed grown, improvement of water-saving efficiency, ratio of foodstuff, cotton, oil, fruit may reach 24:1:8:7 recently. The proportion of wheat and corn in the southern region is 1:1. Average ratio of total output value of agriculture, forestry, animal husbandry, fisheries may reach 100:1:70:10 recently. And structure of wheat and corn in northern areas is basically unchanged. 
(3) Advantageous regions of cotton and oil: the area soil is mainly moisture soil, pickled moisture soil, low-lying, easy to form the floods. But this region must strengthen water conservancy construction and improve soil fertility. The plant structure is large-scale cultivation of high-quality fuel, high-quality cotton, compressed wheat and corn acreage, moderate development of fodder cultivation, increasing areas of mechanized operations. Meanwhile, this region should depend mainly on the development of cotton and oil processing industry and develop export-oriented industries.

From 2000 to 2006 in this area, average proportion of the acreage of foodstuff, cotton, oil was 4.5:1:1.1; Average ratio of total output value of agriculture, forestry, animal husbandry, fisheries is $27: 1.5: 12: 1$. The ratio of foodstuff, cotton, oil may reach 3:1:1.1 recently. Average ratio of total output value of agriculture, forestry, animal husbandry, fisheries may reach 20:2.5:14:1 which was the optimized structure recently.

(4) Advantageous regions of foodstuff and cotton: the soil is moisture soil with saline. It should develop water-saving foodstuff and cotton production, and modestly reduce cotton acreage and expand corn acreage. While Anhui north plain areas have obvious advantages of water resources, should increase the special corn production. This area should plant food, cash crops and fodder crops, and Anhui north plains should increase a modern planting effort.

From 2000 to 2006, in Anhui north plains, average proportion of the acreage of foodstuff, cotton, oil is 14:1:1.2, among them, wheat and corn was $3: 1$; Average ratio of total output value of agriculture, forestry, animal husbandry, fisheries is $15: 1: 7: 2.5$. The ratio of foodstuff, cotton, oil may reach 12:3:1. Average ratio of total output value of agriculture, forestry, animal husbandry, fisheries may reach 16:1:12:4 which is the optimized structure.

(5)Advantageous region of foodstuff: This area is only suitable for growing food crops, unsuitable for cotton and oil crops. The zones should strengthen a combination of water and soil transformation, especially transformation of the coastal saline soil in Anhui north plain. Anhui north plain areas should enhance scale and specialized planting, while other districts should develop comprehensive planting, reducing sown areas of cotton ordinary oil.

From 2000 to 2006, in Anhui north plains, average proportion of the acreage of foodstuff, cotton, oil is 15:1:2. Average ratio of total output value of agriculture, forestry, animal husbandry, fisheries is 20:1:9:4. The ratio of foodstuff, cotton, oil may reach 20:1:3 recently. Average ratio of total output value of agriculture, forestry, animal husbandry, fisheries may reach to $18: 1: 10: 5$ which is the optimized structure recently.

(6) Advantageous region of oil crops: this region is distributed in the plain areas of southeast Henan, Shandong west plain areas and Anhui north plains. The main soil is moisture soil. Areas of this type are only suitable for planting oil-bearing crops, low-producing areas for cotton and food crops. Its agricultural development should lay stress on the combination of water and soil. The goal is to form large-scale oil cultivation and oilseeds areas where oil crops are main cash crops.

From 2000 to 2006, in this area, average proportion of the acreage of foodstuff, cotton, oil, fruit tree is 21:2:6:1. Average ratio of total output value of agriculture, 
forestry, animal husbandry, fisheries is $25: 1: 10: 2$. The ratio of foodstuff, cotton, oil, fruit tree may reach 10:3:10:1 recently. Average ratio of total output value of agriculture, forestry, animal husbandry, fisheries may reach 16:1:12:2 which was the optimized structure recently.

(7) Advantageous region of cotton: the main soil is moisture soil. Areas of this type are only suitable for growing cotton, low-producing areas for foodstuff and oil crops. In Heilonggang areas should water-saving cropping patterns should be developed, combining water-saving with soil improvement. Anhui north plains should base on large-scale, specialized cultivation and develop cotton-based of various business models.

From 2000 to 2006, in this area, the average proportion of the acreage of foodstuff, cotton, oil, fruit, vegetables is 12:3:1.5:1.2:1. Average ratio of total output value of agriculture, forestry, animal husbandry, fisheries is $27: 1: 11: 2$. The ratio of foodstuff, cotton, oil, fruit, vegetables may reach 6:4:1:1:1 recently. Average ratio of total output value of agriculture, forestry, animal husbandry, fisheries may reach 12:1:5:1 which is the optimized structure recently.

\subsection{Agricultural Zoning Layout of Middle and Low Producing Areas}

Middle and low producing areas in the Plain areas is quite large, covering more than 110 counties (cities). They were mainly affected by drought, waterlog, salinity, wind and sand, lime concretion, barren and other barriers element[8]. Due to a poor efficiency of the ecological environment, the region should improve the ecological environment through ecological structural adjustment. By using salt-tolerant, bio-cover and bio-drainage to change the movement of soil water and salt, it will gain ecological and economic benefits. The region can plant forest and foodstuff, vegetable in salinity lighter areas, and plant salt-tolerant vegetation in salinity areas. By using water-saving irrigation techniques, straw, organic fertilizers to improve soil structure and increase soil fertility, this region should save and protect water resources to achieve the target of high and stable yield.

In the northern parts of the region is mainly moisture soil and bog soil, while in the south is mainly moisture soil and lime concretion black soil. Controlling saline-alkali soil in the area is a long-term arduous task. The region needs to increase agricultural inputs and strengthen water conservancy measures. In addition, improvement of saline-alkali soil is also very important. The control of sand is a focus of the area, which should be based on biological measures and engineering measures, and combine forestry fruit with flowers and grass. Then the region can establish a sand ecological and economic protection system. The southern part should focus on improving lime concretion black soil and created farmland shelterbelts and establishing three-dimensional forest shelter, fertilizing organic materials and planting green manure. The northern parts should focus on water-saving agriculture, and developing various patterns of water-saving cropping [9].

From 2000 to 2006, in this area, the average proportion of the acreage of foodstuff, cotton, oil, fruit tree, vegetables was 20:1:2:1.2:2. Average ratio of total output value of agriculture, forestry, animal husbandry, fisheries is $30: 1: 16: 2$. The ratio of foodstuff, 
cotton, oil, fruit tree, vegetables may reach 15:1:5:4:5 recently. Average ratio of total output value of agriculture, forestry, animal husbandry, fisheries may reach 25:1:15:2 which is the optimized structure recently.

\section{Conclusion}

This is a quantitative research, so the paper has got one step further than previous studies. Because of the huge workload of quantitative research, the author can only make a streamlined introduction in this paper. Accurate quantitative studies have yet to be further deepened. However, this study played a guiding role in agricultural development of the Huang-Huai-Hai Plain.

\section{References}

1. Luo, F., Lin, Y.: The application and research of GIS technology in the Fujian agricultural resources. Fujian Soil and Water Conservation 16, 5-9 (2004)

2. Tang, H.: Remote Sensing Technology in Rural Resources Planning and Prospects. China Agricultural Resources and Regional Planning 20, 23-26 (1999)

3. Bi, Y., Jiang, W., Xu, B.: Rational use of agricultural resources and ideas of protecting zones' research. China Agricultural Resources and Regional Planning 25, 58-61 (2006)

4. A-Amrieh, Sabbah, W., Isaac, J.: Impact of irrigated agricultural practices on environmental quality and human health in the West Bank. American Journal of Alternative Agriculture 14, 165-170 (1999)

5. Robertson, A.I.: The gaps between ecosystem ecology and industrial agriculture ecosystems. American Journal of Alternation Agriculture 3, 413-418 (2000)

6. Ministry of Agriculture: Regional distribution planning of competitive agricultural products. China Agriculture Press, Beijing (2003)

7. Wu, K., Huang, R.: Sustainability assessment of soil and water resources use, development potential and Countermeasures in Huang-Huai-Hai plain. Geographical Sciences 21, 391-395 (2001)

8. Sun, H., Shi, Y.: China's natural agricultural and regional development. Jiangsu Science and Technology Press, Nanjing (1994)

9. Hou, M., Hao, J., Ding, Z.: Research of low consumption resources of ecological agriculture in Huang-Huai-Hai plain. Chinese Ecological Agriculture Journal 13, 189-191 (2005) 